\title{
Advancing Integrated Family Planning (FP)/HIV Counseling with Evidence (ADVICE): Review of FP decision support tools and HIV vulnerability assessment tools
}

\author{
Eileen Yam \\ Population Council \\ Tracy McClair \\ Population Council
}

Follow this and additional works at: https://knowledgecommons.popcouncil.org/departments_sbsr-hiv How does access to this work benefit you? Let us know!

\section{Recommended Citation}

Yam, Eileen and Tracy McClair. 2021. "Advancing Integrated Family Planning (FP)/HIV Counseling with Evidence (ADVICE): Review of FP decision support tools and HIV vulnerability assessment tools." Washington, DC: Population Council. 
ADVANCING INTEGRATED FAMILY PLANNING (FP)/HIV COUNSELING WITH EVIDENCE (ADVICE): REVIEW OF FP DECISION SUPPORT TOOLS AND HIV VULNERABILITY ASSESSMENT TOOLS

\section{Elleen Yam \\ Tracy McClair} COUNCIL 


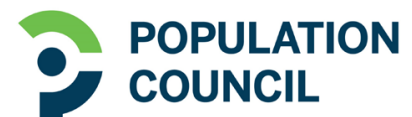 \\ Ideas. Evidence. Impact.}

The Population Council confronts critical health and development issues-from stopping the spread of HIV to improving reproductive health and ensuring that young people lead full and productive lives. Through biomedical, social science, and public health research in 50 countries, we work with our partners to deliver solutions that lead to more effective policies, programs, and technologies that improve lives around the world. Established in 1952 and headquartered in New York, the Council is a nongovernmental, nonprofit organization governed by an international board of trustees.

Population Council

4301 Connecticut Avenue NW, Suite 280

Washington, DC 20008

USA

Tel: 202-237-9400

email: info@popcouncil.org

popcouncil.org

Suggested citation: Yam, Eileen and Tracy McClair. 2021. "Advancing Integrated Family Planning (FP)/HIV Counseling with Evidence (ADVICE): Review of FP decision support tools and HIV vulnerability assessment tools." Washington, DC: Population Council. 


\section{Table of contents}

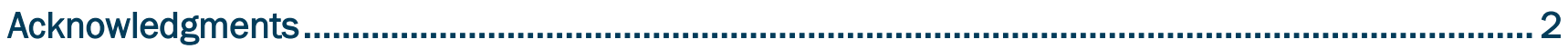

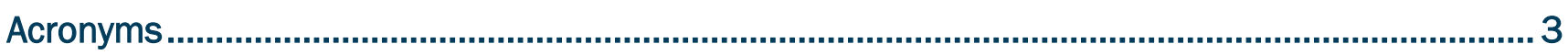

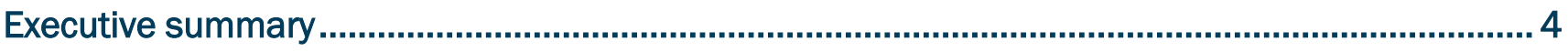

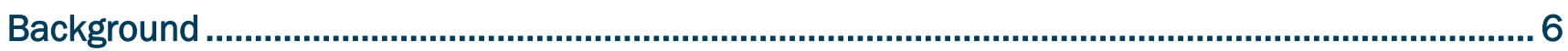

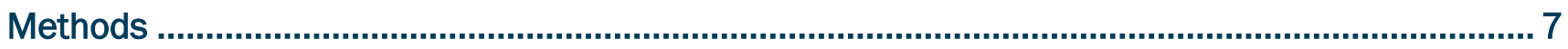

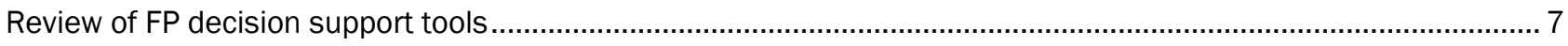

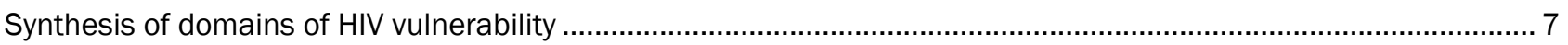

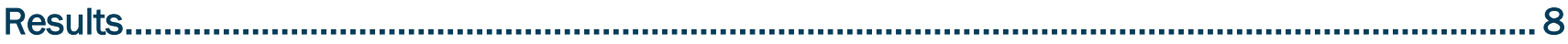

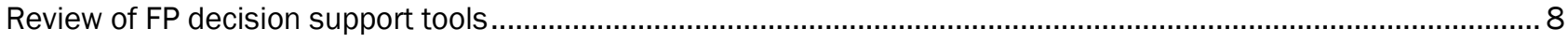

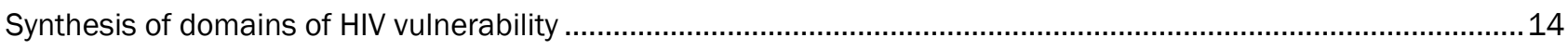

Conclusions and recommendations................................................................................... 17

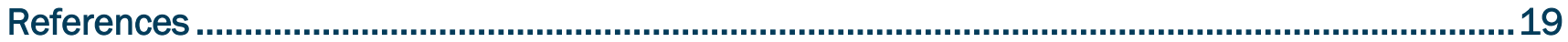




\section{Acknowledgments}

We thank the following scholars, donors, and program managers who provided technical support, insights, and recommendations that informed not only this scoping review, but also our overarching approach to achieving the ADVICE project's aims: Moazzam Ali, James Kiarie, Petrus Steyn (World Health Organization); Jared Baeten, Connie Celum (University of Washington); Beth Mallalieu, Alice Payne Merritt, Douglas Storey (Johns Hopkins Center for Communications Programs); Jay Silverman (University of California San Diego); Jennifer Mason (USAID, Office of Population and Reproductive Health); Ben Bellows (Nivi, Inc.); Michelle Hindin, Karen Kirk, Sanyukta Mathur, Michael Mbizvo, Edith Namukonda, Julie Pulerwitz, Saumya Ramarao, Charlotte Warren (Population Council); and Christine Galavotti, Siobhan Malone (Bill \& Melinda Gates Foundation). 


\section{Acronyms}

$\begin{array}{ll}\text { ADVICE } & \text { Advancing Integrated HIV/FP Counseling with Evidence } \\ \text { ARCHES } & \text { Addressing Reproductive Coercion in Health Settings } \\ \text { ART } & \text { Antiretroviral treatment } \\ \text { BCS/BCS+ } & \text { Balanced Counseling Strategy/Balanced Counseling Strategy Plus } \\ \text { BMGF } & \text { Bill \& Melinda Gates Foundation } \\ \text { CCP } & \text { Johns Hopkins Center for Communication Programs } \\ \text { DMT } & \text { World Health Organization's Decision-Making Tool for Family Planning Clients and Providers } \\ \text { ECHO } & \text { Evidence for Contraceptive Options and HIV Outcomes } \\ \text { FP } & \text { Family planning } \\ \text { GBV } & \text { Gender-based violence } \\ \text { LARC } & \text { Long-acting reversible contraception } \\ \text { LMIC } & \text { Lower- and middle-income country } \\ \text { PrEP } & \text { Pre-exposure prophylaxis } \\ \text { STI } & \text { Sexually transmissted infection }\end{array}$




\section{Executive summary}

Many women are at risk for both unintended pregnancy as well as HIV acquisition, and there is global consensus about the importance of integrating HIV and family planning (FP) services. To help FP providers and clients contemplate whether and how HIV vulnerability may influence contraceptive choices, decision support tools can help providers and clients systematically assess multiple contraceptive options and select the method that meets individual needs and values.

In July 2019, the Population Council ("the Council”) received support from the Bill \& Melinda Gates Foundation to identify and improve strategies for integrating HIV vulnerability assessment in FP counseling contexts, under the Advancing Integrated HIV/FP Counseling with Evidence (ADVICE) project. Specifically, ADVICE aimed to identify and/or improve counseling tools that could support FP clients and providers to consider HIV risk when making contraceptive decisions.

This document summarizes our findings from a scoping review of FP decision support tools and HIV vulnerability assessment tools. We sought to collate basic descriptive information about FP decision support tools, and synthesize HIV vulnerability assessment tools to identify the most relevant risk "domains" that are most pertinent to making contraceptive decisions. We addressed two broad questions:

- Which existing FP decision support tools are promising tools for incorporating stronger HIV vulnerability assessment into FP counseling in lower- and middle-income countries (LMICs)?

- Which HIV vulnerability domains (such as individual behaviors, relationship dynamics) should such tools incorporate, to inform FP clients' contraceptive choices and optimize dual protection?

The scoping review consisted of searches of peer-reviewed literature, reviews of project reports, and inquiries of experts in FP/HIV integration.

Of the 28 identified FP decision support tools, 21 were developed and used in the United States or Europe. Just three had been deployed in more than one LMIC setting. There was a notable proliferation in digital FP decision support tools over time: there was just one identified digital FP decision support tool developed before 2011, increasing to six new tools developed between 2011 and 2015, and to 17 between 2016 and 2021.

Twenty-one tools were used solely in facility settings (either as provider job aids or as client-facing decision aids), and five were digital tools that could be used anywhere the app and/or Internet connectivity was available (in facilities or elsewhere). Half $(n=14)$ of the tools were expressly designed to be used during the pre-consultation "waiting area" time, while clients waited their turn to see the provider.

We reviewed thirty-five HIV vulnerability assessment tools. Thirteen domains of HIV vulnerability were identified. We identified several HIV vulnerability domains that are particularly relevant to explore in the context of FP counseling sessions.

Key recommendations for program managers, donors, and other FP/HIV stakeholders from this scoping review:

- Prioritize strengthening and updating HIV content in FP decision aids that have already been scaled up in LMICs, such as the Balanced Counseling Strategy Plus toolkit or the World Health Organization's DecisionMaking Tool for Family Planning Clients and Providers (DMT).

- Capitalize on "waiting-area" time. In LMICs, these captive minutes and hours when FP clients are waiting is an underutilized opportunity to provide FP/HIV-related decision support to clients and prime them to contemplate whether and how their HIV vulnerability may affect their contraceptive choices.

- Test and evaluate digital tools to provide FP decision support, in service delivery settings and beyond. Digital technology presents a tremendous opportunity to provide users with health information in many settings, whether in the privacy of their homes, at school, or in community contexts. Whereas digital tools in facility settings are intended for users who have already decided to seek care, digital platforms also can be used to educate those who have not yet attended a facility, potentially providing them with a cue to action to get services. 
- To optimize FP decision support, prioritize strategies and tools that promote shared decision-making between providers and FP clients (i.e., tools that "face" both the provider and client).

- To support contraceptive choice, FP decision support tools that incorporate HIV vulnerability counseling should prioritize the following factors that are most pertinent to FP clients making contraceptive decisions:

- Sexually transmitted infection (STI) history

- Alcohol or drug use

- Inconsistent condom use

- Use of dual protection

- Prior HIV testing

$0 \quad>1$ sex partner

- Partner has other sex partners

○ Partner living with HIV

○ Treatment status of partner living with HIV

○ Negotiating power with partner

- Recent experience of gender-based violence (GBV)

This review identified innovative approaches to broadening both the platforms through which FP decision support is offered (digital or otherwise), as well as the timing of lending that support (i.e., during pre-consultation time). In addition, by focusing on the HIV vulnerability domains that are particularly relevant to FP clients, developers of future FP decision support tools can incorporate questions and lines of inquiry that explore whether and how clients' behaviors and characteristics may place them at increased risk of HIV acquisition and inform their contraceptive choices to optimize dual protection. 


\section{Background}

For more than two decades, there has been global consensus among public health professionals, advocates, and researchers about the need for integration of HIV and family planning (FP) services. Many women are at risk both of unintended pregnancy as well as HIV acquisition, and countries with the highest levels of HIV often also have high levels of unmet contraceptive need. These dual prevention needs are particularly salient in light of the June 2019 release of the results from the Evidence for Contraceptive Options and HIV Outcomes (ECHO) trial, which aimed to assess whether HIV acquisition risk differs among users of three contraceptive methods (depot medroxyprogesterone acetate-intramuscular, levonorgestrel implant [Jadelle], and copper intrauterine device). Although the research team found no significant difference in HIV acquisition among FP clients using the three methods-all three were safe and acceptable to participants-there was high overall HIV incidence across method users (3.8 percent). (1) This finding underscored the substantial HIV vulnerability among women seeking FP services, reinvigorating calls to integrate HIV prevention and treatment in FP services.

A persistent challenge for FP providers is the sheer volume of information and contraceptive methods that they are tasked with discussing in a limited amount of time. Therefore, meaningful contemplation of HIV vulnerability can be difficult for FP providers and clients alike, who regard pregnancy prevention as their primary concern. Decision support tools can help providers and clients systematically assess multiple contraceptive options and select the method that meets individual needs and values, (2) and these tools also have the potential to support streamlined incorporation of HIV vulnerability assessment into FP counseling. Ideally, FP decision support tools can facilitate having providers and women contemplate HIV in a systematic, standardized fashion.

In July 2019, shortly following the publication of ECHO results, the Population Council ("the Council") received support from the Bill \& Melinda Gates Foundation (BMGF) to identify and improve strategies for integrating HIV vulnerability assessment in FP counseling contexts, under the Advancing Integrated HIV/FP Counseling with Evidence (ADVICE) project. Specifically, ADVICE aimed to identify and/or improve counseling tools that could support FP clients and providers to consider HIV risk when making contraceptive decisions.

As a first step, we conducted a landscaping exercise-expert interviews, consultations, and a scoping review of the literature-to identify two existing types of tools: (i) FP decision support tools and (ii) HIV vulnerability assessment screening tools. This document summarizes our findings from the scoping review. We sought to collate basic descriptive information about FP decision support tools to better understand, for example, their modalities (e.g., digital, paper), geographic reach (such as their appropriateness for use in lower- and middle-income countries (LMICs)), and suitability for integrating strengthened HIV content. In parallel with the scoping review of FP decision support tools, we also synthesized HIV vulnerability assessment tools to identify the most relevant risk "domains" that need to be probed about in the context of making contraceptive decisions. Collectively, taking our findings from these two reviews in tandem, we sought to answer two broad questions:

- Which existing FP decision support tools are promising tools for incorporating stronger HIV vulnerability assessment into FP counseling in LMICs?

- Which HIV vulnerability domains (such as individual behaviors, relationship dynamics) should such tools incorporate, to inform FP clients' contraceptive choices and optimize dual protection?

Findings from the expert interviews and scoping review informed the subsequent development and testing of an ADVICE chatbot to support FP clients to self-assess HIV vulnerability in Zambian FP clinic waiting areas, for which we achieved proof of concept in a field test in Lusaka in March 2021. 


\section{Methods}

\section{REVIEW OF FP DECISION SUPPORT TOOLS}

We included in our scoping review FP decision support tools that were identified by experts whom we interviewed, as well as tools identified in a review of the literature, limiting our search to those tools that have been described in peer-reviewed journals. Recognizing the vast proliferation of FP job aids and decision support tools in recent years, we limited our search in this manner to ensure that our review focused on tools that were designed with a degree of conceptual and technical rigor. We identified tools by searching peerreviewed literature via the scholarly databases Google Scholar and PubMed, employing search terms "contraception and counselling tool or decision support or algorithm or job aid," and "family planning and counselling tool or decision support or algorithm or job aid." We reviewed articles to identify and include tools that provide a systematic manner of facilitating contraceptive decision-making. We did not impose date restrictions on the search. In addition, we searched the reference lists of identified articles to include additional relevant tools that were cited. ${ }^{1}$ The included articles consisted of papers describing the development of the tools, descriptions of protocols for deploying or evaluating the tools, and evaluation studies examining the outcomes of tool use. In addition, in cases where we were able to identify gray literature (such as project reports) that substantiate peer-reviewed articles, we also reviewed those documents.

For each of the identified tools, we collated the following information, adding characteristics of interest in an iterative fashion as the articles were reviewed.

- Basic description of the tool

- Modality (i.e., digital versus non-digital)

- Intended setting (i.e., facility versus nonfacility)
- $\quad$ Timing of use (i.e., pre-consultation versus not)

- Geography (i.e., LMIC versus exclusively highincome country)

- Intended population

\section{SYNTHESIS OF DOMAINS OF HIV VULNERABILITY}

We conducted expert interviews and a desk review to identify HIV vulnerability assessment tools from which to synthesize characteristics and behaviors that are associated with increased risk of HIV acquisition, with the aim of identifying a subset of these factors that would be most pertinent in the context of a FP counseling session, to inform contraceptive choice. The literature review included articles and tools from databases (PubMed, Web of Science, and Scopus) as well as implementing organizations' websites, World Health Organization (WHO) guidance, and AVAC's PrEPWatch. Inclusion criteria included: tools/articles from 2014 to present, available in English, from any geographic area, used in any setting (community, facility, etc.), and used by any cadre of the health workforce (community health workers, facility staff, etc.). We used the following search terms: HIV risk, HIV vulnerability, tool, assessment, screening, and index. Tools that were focused on men who have sex with men and/or HIV pre-exposure prophylaxis (PrEP) were included. We reviewed all questions from each tool and recorded domains of HIV vulnerability into a spreadsheet, as well as the specific factors (i.e., individual behaviors, interpersonal dynamics, etc.) that fell within each of those domains. Subsequently, based on feedback from interviews and our review of FP decision support tools, we identified a subset of factors to be prioritized for incorporation into FP decision support tools.

1For instance, in December 2019, Cavallaro et al. published a systematic review of the effectiveness of counselling strategies for modern methods, supported by the BMGF. (3) We included in our scoping the tools that were cited in this review paper. To avoid redundancy with the review paper by Cavallaro and colleagues, our scoping review did not synthesize findings on tool effectiveness. 


\section{Results}

\section{REVIEW OF FP DECISION SUPPORT TOOLS}

As summarized in Table 1, we identified 28 FP decision support tools, 27 of which were described in the peer-reviewed literature (in 51 articles), and 1 of which was shared with us one of the interviewed experts (i.e., MyChoice, developed by Johns Hopkins Center for Communication Programs (CCP)). Articles describing the included tools covered a date range of 1999 to 2021.

A large majority of the identified tools (19/28) had been developed and used in the United States, two in Europe, and eight in LMICs (Figure 1). Three tools had been deployed in more than one LMIC setting: Balanced Counseling Strategy/Balanced Counseling Strategy Plus (BCS/BCS+); the WHO's Decision-Making Tool for Family Planning Clients and Providers (DMT); and Addressing Reproductive Coercion in Health Settings (ARCHES).

\section{FIGURE 1 GEOGRAPHIC DISTRIBUTION OF FP DECISION SUPPORT TOOLS (N=28)*}

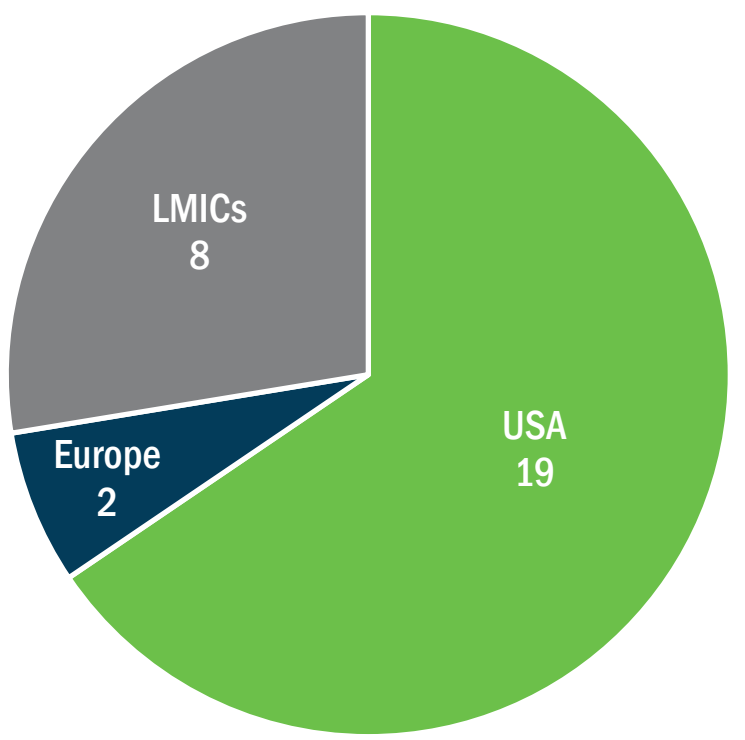

*The frequencies in the pie chart sum to 29 because ARCHES has been used in the US as well as in LMICs.

Twenty-four of the 28 tools were digital, the majority of which were developed in the past five years: there was just 1 identified digital FP decision support tool developed before 2011, 6 were developed between 2011 and 2015, and 17 between 2016 and 2021 (Figure 2). Five of the 24 digital tools had been tested in LMICs. Across countries, the most frequently used digital modalities were Internet-based tools (i.e., accessible anywhere users can access a web browser), and standalone apps that were used on mobile devices or computers. One tool employed "adjunctive social media" consisting of supplemental videos, graphics, and games on a dedicated Facebook page. $(4,5)$ The other FP decision support tools were paperbased, with the exception of one tactile tool that consisted of life-sized replicas of contraceptive methods on a key ring. (6) 


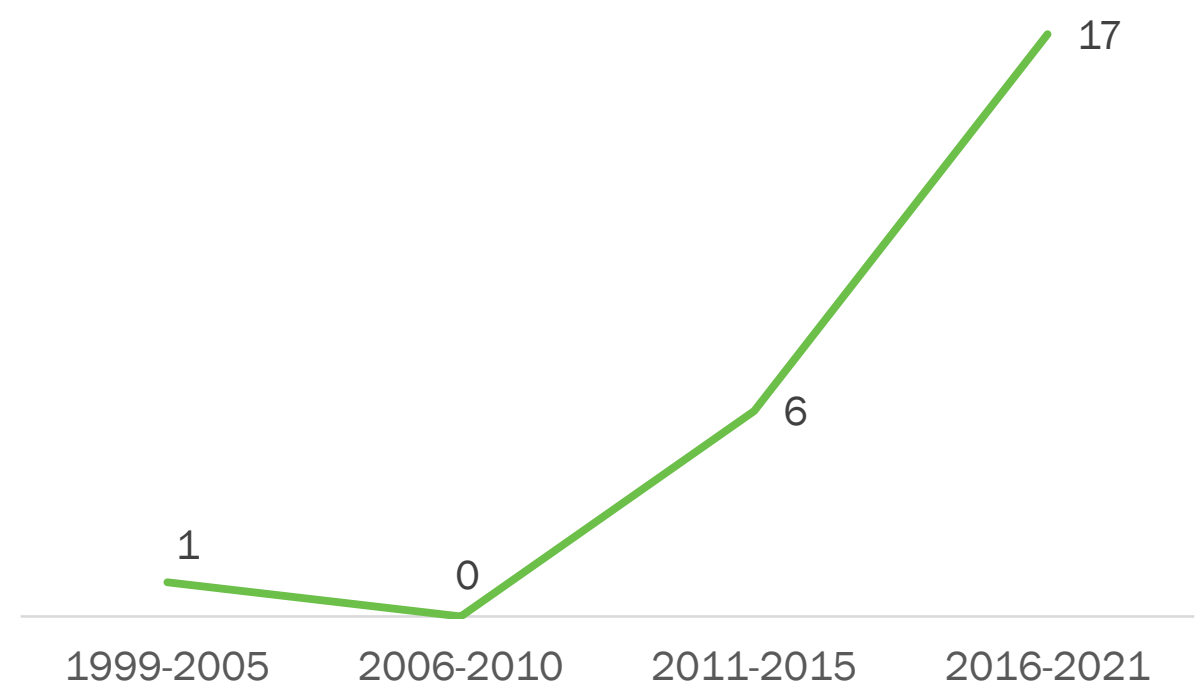

Twenty-one tools were used solely in facility settings (either as provider job aids or as client-facing decision aids), and five were digital tools that could be used anywhere the app and/or Internet connectivity was available (in facilities or elsewhere). Of the remaining two tools, one was a provider-facing digital job aid used by community health workers in Tanzania, $(7,8)$ and a second was an SMS-based intervention among postpartum clients in Kenya. $(9,10)$

Half $(n=14)$ of the tools were expressly designed to be used during the pre-consultation "waiting area time," while clients waited their turn to see the provider. In addition, one tool (Bedsider.org) is Internet-based and accessible on any web browser, but it had also been tested as a waiting-area intervention. (11) These clientfacing tools all aimed to support contraceptive decision-making, with some digital waiting-area tools providing the option of producing a printed, tailored summary of the client's method preferences, for discussion with the provider. (12-18)

Most of the identified FP decision support tools were client-facing aids intended for clients attending FP or OB/GYN services. One tool was tested among Latina adolescents attending school-based health centers in the United States, $(19,20)$ and another was piloted among women of reproductive age attending United States Veterans Affairs primary care clinics. (21) Four were designed for use with adolescents, all in the United States. $(19,20,22-25)$, and several were provider job aids, either provider-facing $(7,8)$ or jointly provider- and client-facing. $(6,26-32)$ 
TABLE 1 FP DECISION SUPPORT TOOLS $(\mathrm{N}=28)$

\begin{tabular}{|c|c|c|c|c|c|c|c|c|}
\hline Year* & Authors/Developer & Tool & Description & Digital & Setting & $\begin{array}{c}\text { Pre-consultation } \\
\text { use }\end{array}$ & Geography & Intended users \\
\hline 1998 & $\begin{array}{l}\text { Population Council }(33- \\
37) \\
\text { Leon et al. }(6,7) \\
\text { Liambila et al. }(29,39)\end{array}$ & $\begin{array}{l}\text { Balanced Counseling } \\
\text { Strategy (BCS)/Balanced } \\
\text { Counseling Strategy Plus } \\
\text { (BCS+) }\end{array}$ & $\begin{array}{l}\text { Paper counseling cards } \\
\text { and algorithm, provider- } \\
\text { and client-facing }\end{array}$ & No & Facility & No & $\begin{array}{l}\text { Global, } \\
\text { predominantly } \\
\text { LMIC }\end{array}$ & FP clients \\
\hline 1999 & Chewning et al. (22) & $\begin{array}{l}\text { Aid for Contraceptive } \\
\text { Decision-making (ACD) }\end{array}$ & $\begin{array}{l}\text { Computer-based } \\
\text { decision aid }\end{array}$ & Yes & Facility & Yes & USA & $\begin{array}{l}\text { Adolescent female FP } \\
\text { clients }\end{array}$ \\
\hline 2005 & $\begin{array}{l}\text { World Health } \\
\text { Organization } \\
\text { Kim et al. }(40,41) \\
\text { Johnson et al. (42) } \\
\text { Langston et al. (43) } \\
\text { Festin et al. (30) }\end{array}$ & $\begin{array}{l}\text { Decision-Making Tool for } \\
\text { Family Planning Clients } \\
\text { and Providers (DMT) }\end{array}$ & $\begin{array}{l}\text { Two-sided flipchart: one } \\
\text { side a decision aid for } \\
\text { clients, the other side a } \\
\text { job aid for providers }\end{array}$ & No & Facility & No & $\begin{array}{l}\text { Global, } \\
\text { predominantly } \\
\text { LMIC }\end{array}$ & FP providers and clients \\
\hline 2012 & Garbers et al. $(44,45)$ & Best Method for Me & $\begin{array}{l}\text { Computer-based } \\
\text { contraceptive } \\
\text { assessment module }\end{array}$ & Yes & Facility & Yes & USA & $\begin{array}{l}\text { English- or Spanish- } \\
\text { speaking women at FP } \\
\text { clinics }\end{array}$ \\
\hline 2014 & Gilliam et al. (46) & (Unnamed digital app) & $\begin{array}{l}\text { iOS waiting room app to } \\
\text { increase } \\
\text { long-acting reversible } \\
\text { contraception (LARC) } \\
\text { awareness }\end{array}$ & Yes & Facility & Yes & USA & Clients at Title $\mathrm{X}$ clinics \\
\hline 2014 & Kofinas et al. $(4,5)$ & $\begin{array}{l}\text { (Unnamed adjunctive } \\
\text { social media intervention) }\end{array}$ & $\begin{array}{l}\text { Contraceptive education } \\
\text { provided in video, } \\
\text { diagrams, and game } \\
\text { format over a Facebook } \\
\text { page, following provider } \\
\text { counseling }\end{array}$ & Yes & $\begin{array}{l}\text { Tested in facility, } \\
\text { but could be } \\
\text { used anywhere }\end{array}$ & No & USA & OB/GYN clients \\
\hline 2014 & $\begin{array}{l}\text { Wilson et al. (16) } \\
\text { Koo et al. (17) }\end{array}$ & Smart Choices & $\begin{array}{l}\text { Computer-based } \\
\text { (downloadable) } \\
\text { contraceptive } \\
\text { counseling aid with } \\
\text { printout summary of } \\
\text { patient preferences }\end{array}$ & Yes & Facility & Yes & USA & FP clients \\
\hline
\end{tabular}




\begin{tabular}{|c|c|c|c|c|c|c|c|c|}
\hline Year* & Authors/Developer & Tool & Description & Digital & Setting & $\begin{array}{c}\text { Pre-consultation } \\
\text { use }\end{array}$ & Geography & Intended users \\
\hline 2015 & Sridhar et al. $(47,48)$ & $\begin{array}{l}\text { Plan A Birth Control (Plan } \\
\text { ABC) }\end{array}$ & $\begin{array}{l}\text { Mobile app providing } \\
\text { information on most } \\
\text { common nonpermanent } \\
\text { methods, emphasis on } \\
\text { LARC }\end{array}$ & Yes & Facility & Yes & USA & OB/GYN clients \\
\hline 2015 & $\begin{array}{l}\text { National Campaign to } \\
\text { Prevent Teen and } \\
\text { Unplanned Pregnancy } \\
\text { Gressel et al. (49) } \\
\text { Antonishak et al. (50) } \\
\text { Giho et al. (11) }\end{array}$ & Bedsider.org & $\begin{array}{l}\text { Website with } \\
\text { contraceptive decision } \\
\text { aid, tools to help find } \\
\text { nearest location to } \\
\text { obtain methods }\end{array}$ & Yes & $\begin{array}{l}\text { Accessible } \\
\text { anywhere via } \\
\text { Internet, and has } \\
\text { been tested as a } \\
\text { waiting-area tool }\end{array}$ & $\begin{array}{l}\text { Yes, but can be } \\
\text { used anywhere }\end{array}$ & USA & $\begin{array}{l}\text { Potential FP users (who } \\
\text { can access tool via } \\
\text { Internet) }\end{array}$ \\
\hline 2015 & $\begin{array}{l}\text { Tancredi et al. (51) } \\
\text { Miller et al. (52,53) } \\
\text { Uysal et al. (54) }\end{array}$ & $\begin{array}{l}\text { Addressing Reproductive } \\
\text { Coercion in Health } \\
\text { Settings (ARCHES) }\end{array}$ & $\begin{array}{l}\text { Paper aid focused on } \\
\text { intimate partner } \\
\text { violence, supports } \\
\text { method choice when } \\
\text { partner not amenable to } \\
\text { contraceptive use }\end{array}$ & No & Facility & No & $\begin{array}{l}\text { USA, Mexico, } \\
\text { Kenya, } \\
\text { Bangladesh }\end{array}$ & FP clients \\
\hline 2016 & $\begin{array}{l}\text { Agarwal et al. (7) } \\
\text { Braun et al. (8) }\end{array}$ & (Unnamed mobile job aid) & $\begin{array}{l}\text { Mobile app to support } \\
\text { community health } \\
\text { workers counsel on FP, } \\
\text { HIV, STIs }\end{array}$ & Yes & Community & No & Tanzania & $\begin{array}{l}\text { Community health } \\
\text { workers }\end{array}$ \\
\hline 2017 & Tebb et al. $(19,20)$ & Health-E You/Salud iTu & $\begin{array}{l}\text { Spanish mobile app } \\
\text { providing contraceptive } \\
\text { decision support }\end{array}$ & Yes & Facility & Yes & USA & $\begin{array}{l}\text { Latina adolescents } \\
\text { attending school-based } \\
\text { health centers }\end{array}$ \\
\hline 2017 & Chuang et al. $(55,56)$ & MyNewOptions & $\begin{array}{l}\text { Web-based reproductive } \\
\text { life planning }\end{array}$ & Yes & $\begin{array}{l}\text { Accessible } \\
\text { anywhere via } \\
\text { Internet }\end{array}$ & No & USA & $\begin{array}{l}\text { Potential FP users (who } \\
\text { can access tool via } \\
\text { Internet) }\end{array}$ \\
\hline 2017 & Jamin et al. (57) & $\begin{array}{l}\text { Contraception: HeLping for } \\
\text { wOmen's choicE (CHLOE) }\end{array}$ & $\begin{array}{l}\text { Online questionnaire, } \\
\text { can also be given as } \\
\text { paper copy }\end{array}$ & Yes & Facility & Yes & Europe & FP clients \\
\hline 2017 & $\begin{array}{l}\text { Kaiser Permanente } \\
\text { Northern California } \\
\text { Marshall et al. (58) }\end{array}$ & Birth Control Navigator & $\begin{array}{l}\text { Web-based } \\
\text { contraceptive decision } \\
\text { support tool }\end{array}$ & Yes & $\begin{array}{l}\text { Accessible } \\
\text { anywhere via } \\
\text { Internet }\end{array}$ & Yes & USA & $\begin{array}{l}\text { Potential FP users (who } \\
\text { can access tool via } \\
\text { Internet) }\end{array}$ \\
\hline
\end{tabular}




\begin{tabular}{|c|c|c|c|c|c|c|c|c|}
\hline Year* & Authors/Developer & Tool & Description & Digital & Setting & $\begin{array}{c}\text { Pre-consultation } \\
\text { use }\end{array}$ & Geography & Intended users \\
\hline 2017 & $\begin{array}{l}\text { Dehlendorf et al. (12-14) } \\
\text { Holt et al. (15) }\end{array}$ & My Birth Control & $\begin{array}{l}\text { Web-based } \\
\text { contraceptive decision } \\
\text { support tool, with } \\
\text { printout summary of } \\
\text { patient preferences }\end{array}$ & Yes & Facility & Yes & USA & FP clients \\
\hline 2018 & Tiu et al. (25) & Tia & $\begin{array}{l}\text { Mobile app } \\
\text { contraceptive decision- } \\
\text { making aid }\end{array}$ & Yes & $\begin{array}{l}\text { Accessible } \\
\text { anywhere user } \\
\text { downloads app }\end{array}$ & No & USA & Teenagers \\
\hline 2018 & $\begin{array}{l}\text { Marie Stopes } \\
\text { International } \\
\text { Bates et al. (26) }\end{array}$ & $\begin{array}{l}\text { Digital Counselling } \\
\text { Application (DCA) }\end{array}$ & $\begin{array}{l}\text { Tablet-based FP } \\
\text { counselling app to guide } \\
\text { provider questions }\end{array}$ & Yes & Facility & No & Vietnam, Ethiopia & $\begin{array}{l}\text { Providers and clients at } \\
\text { Marie Stopes } \\
\text { International clinics }\end{array}$ \\
\hline 2018 & $\begin{array}{l}\text { Hebert et al. (23) } \\
\text { Akinola et al. (24) }\end{array}$ & miPlan & $\begin{array}{l}\text { Mobile app for providing } \\
\text { information on } \\
\text { contraceptive options }\end{array}$ & Yes & Facility & Yes & USA & $\begin{array}{l}\text { Young African American } \\
\text { and Latina women }\end{array}$ \\
\hline 2019 & $\begin{array}{l}\text { Johns Hopkins Center for } \\
\text { Communication } \\
\text { Programs (59) }\end{array}$ & MyChoice & $\begin{array}{l}\text { Tablet-based app } \\
\text { version of Balanced } \\
\text { Counseling Strategy } \\
(60)\end{array}$ & Yes & Facility & No & Indonesia & FP clients and providers \\
\hline 2019 & $\begin{array}{l}\text { Thompson et al. (61) } \\
\text { Munro et al. (31) }\end{array}$ & Right for Me & $\begin{array}{l}\text { Video, paper prompt } \\
\text { card, and decision aids } \\
\text { for use by providers with } \\
\text { patients }\end{array}$ & Yes & Facility & No & USA & $\begin{array}{l}\text { Providers and clients at } \\
\text { health clinics that offer } \\
\text { FP }\end{array}$ \\
\hline 2019 & Harrington et al. $(9,10)$ & $\begin{array}{l}\text { Mobile WACh mHealth } \\
\text { platform }\end{array}$ & $\begin{array}{l}\text { SMS messages sent to } \\
\text { postpartum women, } \\
\text { with option to include } \\
\text { male partners }\end{array}$ & Yes & Community & No & Kenya & Postpartum women \\
\hline 2019 & Dev et al. (62) & $\begin{array}{l}\text { Interactive Mobile } \\
\text { Application for } \\
\text { Contraceptive Choice } \\
\text { (iMACC) }\end{array}$ & $\begin{array}{l}\text { Client-facing mobile app } \\
\text { decision aid }\end{array}$ & Yes & Facility & Yes & Kenya & Postpartum women \\
\hline
\end{tabular}




\begin{tabular}{|c|c|c|c|c|c|c|c|c|}
\hline Year* & Authors/Developer & Tool & Description & Digital & Setting & $\begin{array}{c}\text { Pre-consultation } \\
\text { use }\end{array}$ & Geography & Intended users \\
\hline 2019 & Madrigal et al. (32) & $\begin{array}{l}\text { Family Planning Quotient } \\
\text { (FPQ) and Reproductive } \\
\text { Life Index (RepLI) }\end{array}$ & $\begin{array}{l}\text { Computer-based visual } \\
\text { tool to facilitate } \\
\text { reproductive life } \\
\text { planning conversations } \\
\text { between providers and } \\
\text { clients }\end{array}$ & Yes & Facility & Yes & USA & $\begin{array}{l}\text { FP providers and } \\
\text { patients }\end{array}$ \\
\hline 2019 & $\begin{array}{l}\text { de Molina-Férnandez et } \\
\text { al. (27) }\end{array}$ & SHARECONTRACEPT & $\begin{array}{l}\text { Web-based shared } \\
\text { decision-making tool on } \\
\text { hormonal contraception }\end{array}$ & No & Facility & No & Spain & FP providers and clients \\
\hline 2020 & Madden et al. (18) & (Unnamed decision aid) & $\begin{array}{l}\text { Tablet-based decision } \\
\text { aid, tailored printouts } \\
\text { for sharing with provider }\end{array}$ & Yes & Facility & Yes & USA & FP clients \\
\hline 2021 & Lee et al. (6) & Hello Options & $\begin{array}{l}\text { Tangible, life-size } \\
\text { models of methods on a } \\
\text { key ring }\end{array}$ & No & Facility & No & USA & FP providers and clients \\
\hline 2021 & Callegari et al. (21) & MyPath & Web-based decision aid & Yes & Facility & Yes & USA & $\begin{array}{l}\text { Women of reproductive } \\
\text { age attending Veterans } \\
\text { Affairs primary care } \\
\text { clinics }\end{array}$ \\
\hline
\end{tabular}

*The indicated year corresponds to the first published article describing the tool in the peer-reviewed literature. In cases where the tool was an institutional product-such as Balanced Counseling Strategy (Population Council) or Birth Control Navigator (Kaiser Permanente), we indicate the institutional developer's name in addition to the author(s) of the publication(s) describing the tool. 


\section{SYNTHESIS OF DOMAINS OF HIV VULNERABILITY}

To synthesize the individual and interpersonal characteristics and behaviors that are associated with increased vulnerability of HIV acquisition, we reviewed 35 unique HIV vulnerability assessment tools, 9 of which were described in academic literature $(7,63-70)$ and 26 of which were identified in gray literature or through expert interviews (see text box).

From the tools we reviewed, we identified 14 overarching domains of HIV vulnerability, each of which encompassed various characteristics or behaviors that were included in the tools. Different tools often phrased the same concept somewhat differently, so some of the items are not necessarily mutually exclusive (Table 2 ). Based on consultations with FP/HIV experts and our review of FP decision support tools, we selected the following domains of HIV vulnerability as characteristics/behaviors that are particularly appropriate to explore in the context of a FP counseling session:

- $\quad$ STI history

- Alcohol or drug use

- Inconsistent condom use

- Use of dual protection

- $\quad$ Prior HIV testing

- $\quad>1$ sex partner

- Partner has other sex partners

- $\quad$ Partner living with HIV

- Treatment status of partner living with HIV

- Negotiating power with partner

- Recent experience of GBV

\section{HIV vulnerability assessment tools}

1. University of California, Los Angeles, PrEP Adherence Enhancement Guided by iTAB and Drug Levels for Women (AEGis) study screening

2. Amsterdam PrEP (AMPrEP) baseline questionnaire

3. Benin Demonstration Project HIV risk assessment

4. Durbar (DMSC) and Ashodaya Samithi HIV risk assessment

5. HIV Prevention Trials Network (HPTN) 082 Baseline Survey

6. Jlinde/NASCOP PrEP Rapid Assessment Screening Tool (RAST)

7. LVCT Introducing PrEP into HIV Combination Prevention (IPCP) Demonstration Project risk assessment tools

8. Monitoring PrEP in Young Adult Women (MPYA) inclusion criteria and risk score

9. Nigerian National Agency for the Control of AIDS behavior assesements

10. New Zealand (NZ) PrEP inclusion criteria

11. Prevention Options for Women Evaluation Research (POWER) study tools

12. PROUD (pilot trial) eligibility criteria and baseline questionnaire

13. PSI New Start PrEP eligibility risk assessment tool

14. Sauti Vulnerable Adolescent Girls and Young Women's (VAGYW) Index

15. Sustainable East Africa Research in Community Health (SEARCH) study risk score

16. Sibanye, Health4Men Project screening questionnaire for study eligibility

17. International Training and Education Center for Health (I-TECH) PrEP screening tool

18. WHO Implementation Tool for PrEP of HIV Infection

19. ICAP PrEP Screening for Substantial Risk and Eligibility tool

20. CDC HIV Risk Reduction Tool

21. CDC PrEP for the Prevention of HIV Infection in the United States Clinical Providers' Supplement

22. Balanced Counseling Strategy + algorithm and STI and HIV Risk Assessment

23. WHO Decision-Making Tool for Family Planning Clients and Providers: Module on provider-initiated HIV testing and counselling

24. FHI360 Risk Reduction, Assessment, Planning, and Support Toolkit (RRAPS) for HIV Prevention

25. Johns Hopkins Center for Communication Programs One Community Risk Assessment Tool

26. CCP HIV Response Coordination Community Capacity Communication (HC4) Personal Risk Assessment for Men 
TABLE 2 HIV VULNERABILITY DOMAINS

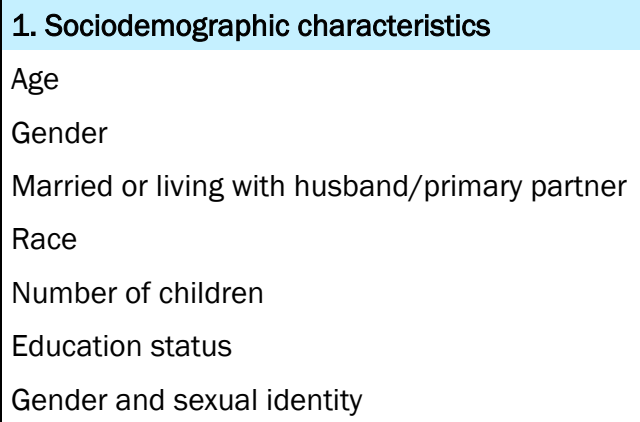

\section{Economic characteristics}

Partner provides financial or material support

Adult in household/community for emotional/financial support

Savings habits

Lost a source of income (such that you may need to exchange sex)

3. STIs

STI history (based on lab testing, self-report, syndromic treatment)*

HSV-2 serostatus

Syphilis

Bacterial vaginosis

Vaginal candidiasis

\section{Substance use}

Alcohol or drug use*

Recurrent sex under the influence of alcohol and/or drugs

\section{Condom use}

Unprotected anal sex

Inconsistent condom use*

Condom use/dual protection*

6. Experience with HIV services (preventive, diagnostic, or treatment)

Post-exposure prophylaxis use

Have used or wanted to use PrEP

Prior HIV testing*

On antiretroviral treatment (ART)

Low HIV knowledge

Prevention of mother-to-child transmission of HIV

PrEP

Circumcised

\section{Sexual behaviors}

Sex role (top vs. bottom)

Group sex

More than 1 sex partner*

Condomless sex with $1+$ male partners of unknown HIV status

Number of casual male partners

Number of sexual partners

Anal sex

Vaginal or anal sexual intercourse without a condom with $>1$ partner

Number of insertive or receptive anal intercourse episodes Use of lubricants

Unprotected sex with non-regular partner

\section{Family planning and pregnancy}

Contraceptive use

Pregnancy

Desire pregnancy

\section{Transactional sex}

Transactional sex

Number of clients

Duration in sex work

Whether or not provide sex work services outside of brothel

Percent of drunk sex work clients

Presence of pimp and condom use with him

Contract arrangement with brothel 


\section{Partner characteristics}

Partner has other sexual partners*

Uncircumcised male partner

Number of HIV-negative anal sex partners

Has at least 1 HIV-positive sexual partner for $\geq 4$ weeks

Sex with HIV-positive partner with unknown or detectable viral load

Partner's HIV status*

Main sex partner HIV positive or unknown status

Having sex with someone who is HIV positive AND not on effective treatment

Viral load of partner

Partner is HIV-positive and on ART*

Male partner who is HIV-positive

Plasma HIV1 RNA in HIV1 positive partner

Having sex with someone who has HIV

Having sex with someone with unknown HIV status

Age of HIV-negative partner

Uncircumcised male HIV-negative partner

Having 1 HIV-negative partner only

Partner's risk status

Have a sex partner with 1+ HIV risk (living with HIV, inject drugs, sex with men, transgender, sex worker, sex with male partner without condoms)

Age difference between sexual partner

Partner has STI

Partner's attitude toward condom use
11. Perceptions, norms, beliefs, and power

Perceived HIV risk

Negotiating power with partner*

Justifies wife beating

\section{Social support}

Existence of social support

\section{GBV}

Recent experience of GBV*

Past experience of sexual violence

Forced to leave your home (especially due to sexual orientation or violence)

\section{Other vulnerabilities}

Key population group

Sexual orientation

Age at sexual debut

Delayed sexual debut

High HIV prevalence population or geographical location

Migration in last 6 months

Polygamy vs. monogamy

Ever had sex

Went to sleep hungry

Malnourished

Left school earlier than planned

Child of person living with HIV

TB status

*Based on expert consultations and review of FP decision support tools, these characteristics and behaviors associated with HIV vulnerability are particularly relevant in the context of FP counseling. 


\title{
Conclusions and recommendations
}

\author{
Prioritize strengthening and updating HIV content in FP decision aids that have already been \\ scaled up in LMICs.
}

Based on the reviewed articles, most of the identified FP decision support tools were developed in the context of discrete, one-off research projects, primarily in high-income countries. For LMICs, the most widely used and tested tools were the Population Council's BCS/BCS+ toolkit, and the WHO's DMT. Because of their substantial global use and recognition, these tools are promising platforms for strengthening HIV/FP integration in existing FP decision support tools.

\section{Capitalize on "waiting-area" time.}

A notable, unanticipated finding from this scoping review was the preponderance of FP decision support tools expressly designed for use by FP clients waiting their turn to see their providers in the "waiting area" of facilities. In LMICs, these captive minutes and hours when FP clients are waiting may be a valuable opportunity to impart HIV information and prime them to contemplate whether and how their HIV vulnerability may affect their contraceptive choices. Such pre-consultation decision support may offload discrete counseling content from overburdened, timeconstrained providers. As noted by French and colleagues, "decision aids have as yet unexploited potential as preconsultation tools." (2)

\section{Test and evaluate digital tools to provide FP decision support, in service delivery settings and beyond.}

Although most of the identified digital tools were intended to be used at the time of the FP client's interaction with a provider, mobile apps and web-based tools are, in theory, accessible anywhere that users have access to the application or web page. Digital technology presents a tremendous opportunity to provide users with health information-whether on FP, HIV, or any number of issues-in many settings, whether in the privacy of their homes, at school, or in community contexts. Whereas digital tools in facility settings are intended for users who have already decided to seek care, digital platforms can also be used to educate those who have not yet attended a facility, potentially providing them with a cue to action to get services. Digital modalities may be particularly promising for younger users, who may have greater fluency and comfort with navigating apps and the Internet, compared to older users. $(19,24,25)$ Pilot tests of digital tools in LMICs suggest that these strategies may be feasible in a range of settings, as long as connectivity, digital literacy, and access to devices are sufficient. $(7,26,62)$

\section{To optimize FP decision support, prioritize strategies and tools that promote shared decision- making between providers and FP clients.}

Ideally, even in cases when FP decision support tools are client-facing, the tools would also include an option for sharing information with providers to discuss together. Whether via a printed summary of clients' entries in a digital waiting-area app or a paper tool that is both provider- and client-facing (such as BCS+ or DMT), the counseling session should incorporate both the provider's medical expertise and the client's individual preferences, on equal footing. (71) Tools that "face" the provider and client facilitate the sharing of information from both parties. 


\section{There are a variety of individual and interpersonal factors that increase FP clients' HIV vulnerability. Decision support tools should prioritize these factors to support contraceptive choice while considering HIV vulnerability.}

In our review of HIV vulnerability assessment tools, we identified an array of vulnerabilities that are associated with increased HIV acquisition risk. To support contraceptive choice, FP decision support tools that incorporate HIV vulnerability counseling can prioritize the following factors that are most pertinent to FP clients making contraceptive decisions:

- STI history

- Alcohol or drug use

- Inconsistent condom use

- Use of dual protection

- $\quad$ Prior HIV testing

- $\quad>1$ sex partner

- Partner has other sex partners

- Partner living with HIV

- Treatment status of partner living with HIV

- Negotiating power with partner

- Recent experience of GBV

This review identified innovative approaches to broadening both the platforms through which FP decision support is offered (digital or otherwise), as well as the timing of lending that support (i.e., during pre-consultation time). In addition, by focusing on the HIV vulnerability domains that are particularly relevant to FP clients, developers of future FP decision support tools can incorporate questions and lines of inquiry that explore whether and how clients' behaviors and characteristics may place them at increased risk of HIV acquisition and inform their contraceptive choices to optimize dual protection. Donors, program managers, and FP/HIV stakeholders interested in achieving the dual aims of preventing unintended pregnancy and HIV acquisition can use findings from this review to prioritize and inform strategies for optimizing FP decision support, while being attentive to FP clients' potential vulnerability to HIV. 


\section{References}

1. Ahmed, K. et al. 2019. "HIV incidence among women using intramuscular depot medroxyprogesterone acetate, a copper intrauterine device, or a levonorgestrel implant for contraception: a randomised, multicentre, open-label trial," The Lancet 394(10195): 303-13. doi: 10.1016/S0140-6736(19)31288-7

2. French, R. S., K. Wellings, and F. M. Cowan. 2009. "How can we help people to choose a method of contraception? The case for contraceptive decision aids," J Fam Plann Reprod Health Care 35(4): 219-20. doi: 10.1783/147118909789587169

3. Cavallaro, F. L. et al. 2020. "A systematic review of the effectiveness of counselling strategies for modern contraceptive methods: what works and what doesn't?," BMJ Sex Reprod Health. 46(4): 254-69. doi: 10.1136/bmjsrh-2019-200377

4. Kofinas, J. D. et al. 2014. "Adjunctive social media for more effective contraceptive counseling: a randomized controlled trial," Obstet Gynecol. 123(4): 763-70. doi: 10.1097/AOG.0000000000000172

5. Kofinas, J. et al. 2014. "Randomized controlled trial of adjunctive social media for more effective contraceptive counseling," Obstet Gynecol. 123(Supplement 1): 107S. doi: 10.1097/01.AOG.0000447049.82019.cb

6. Lee, S. Y. et al. 2021. "Provider and patient perspectives on a new tangible decision aid tool to support patient-centered contraceptive counseling with adolescents and young adults," J Pediatr Adolesc Gynecol. 34(1): 18-25. doi: 10.1016/j.jpag.2020.10.004

7. Agarwal, S. et al. 2016. "Family planning counseling in your pocket: a mobile job aid for community health workers in Tanzania." Glob Health Sci Pract. 4(2): 300-10. doi: 10.9745/GHSP-D-15-00393

8. Braun, R. et al. 2016. "An evaluation of a family planning mobile job aid for community health workers in Tanzania," Contraception. 94(1):27-33. doi: 10.1016/j.contraception.2016.03.016

9. Harrington, E. K. et al. 2019. "An mHealth SMS intervention on postpartum contraceptive use among women and couples in Kenya: a randomized controlled trial," Am J Public Health. 109(6): 934-41. doi: 10.2105/AJPH.2019.305051

10. Harrington, E. K. et al. 2019. "Engaging men in an mealth approach to support postpartum family planning among couples in Kenya: a qualitative study," Reprod Health. 16(1): 17. doi: 10.1186/s12978-019-0669-x

11. Giho, Y. et al. 2020. "Feasibility and acceptability of using a web-based contraceptive support tool in a university health clinic," J Am Coll Health. 68(4):336-40. doi: 10.1080/07448481.2019.1577859

12. Dehlendorf, C. et al. 2019. "Cluster randomized trial of a patient-centered contraceptive decision support tool, My Birth Control," Am J Obstet Gynecol. 220(6): 565.e1-565.e12. doi: 10.1016/j.ajog.2019.02.015

13. Dehlendorf, C. et al. 2017. "Development and field testing of a decision support tool to facilitate shared decision making in contraceptive counseling," Patient Educ Couns. 100(7): 1374-81. doi: 10.1016/j.pec.2017.02.009

14. Dehlendorf, C. et al. 2019. "A mixed-methods study of provider perspectives on My Birth Control: a contraceptive decision support tool designed to facilitate shared decision making," Contraception. 100(5): 420-3. doi: 10.1016/j.contraception.2019.08.001

15. Holt, K. et al. 2020. "Patient-provider communication before and after implementation of the contraceptive decision support tool My Birth Control," Patient Educ Couns. 103(2): 315-20. doi: 10.1016/j.pec.2019.09.003

16. Wilson, E. K. et al. 2014. "Feasibility and acceptability of a computer-based tool to improve contraceptive counseling," Contraception. 90(1): 72-8. doi: 10.1016/j.contraception.2014.02.027

17. Koo, H. P., E. K. Wilson, and A. M. Minnis. 2017. "A computerized family planning counseling aid: a pilot study evaluation of Smart Choices," Perspect Sex Reprod Health. 49(1): 45-53. doi: 10.1363/psrh.12016

18. Madden, T. et al. 2020. "Evaluation of a computerized contraceptive decision aid: a randomized controlled trial," Contraception. 102(5): 339-45. doi: 10.1016/j.contraception.2020.08.002

19. Tebb, K. P. et al. 2019. "A mobile health contraception decision support intervention for Latina adolescents: implementation evaluation for use in school-based health centers," JMIR MHealth UHealth. 7(3): e11163. doi: 10.2196/11163 
20. Tebb, K. P. et al. 2018. "Assessing the effectiveness of a patient-centred computer-based clinic intervention, Health-E You/Salud iTu, to reduce health disparities in unintended pregnancies among Hispanic adolescents: study protocol for a cluster randomised control trial," BMJ Open. 8(1): e018201. doi: 10.1136/bmjopen-2017-018201

21. Callegari, L. S. et al. 2021. "Development and pilot testing of a patient-centered web-based reproductive decision support tool for primary care," J Gen Intern Med. Online ahead of print, 4 February. doi: 10.1007/s11606-020-06506-6

22. Chewning, B. et al. 1999. "Evaluation of a computerized contraceptive decision aid for adolescent patients," Patient Educ Couns. 38(3): 227-39. doi: 10.1016/s0738-3991(99)00014-2

23. Hebert, L. E. et al. 2018. "Mobile contraceptive application use in a clinical setting in addition to standard contraceptive counseling: a randomized controlled trial," Contraception. 98(4): 281-7. doi: 10.1016/j.contraception.2018.07.001

24. Akinola, M. et al. 2019. "Development of a mobile app on contraceptive options for young African American and Latina women," Health Educ Behav. 46(1): 89-96. doi: 10.1177/1090198118775476

25. Tiu, J. et al. 2018. "Teenagers' personal preferences for contraceptive decision-making using a digital reproductive health advisor," $J$ Pediatr Adolesc Gynecol. 31(2): 172-3. doi: 10.1016/j.jpag.2018.02.039

26. Bates, L. A. et al. 2018. "Evaluating the impact of Marie Stopes International's digital family planning counselling application on the uptake of long-acting and permanent methods of contraception in Vietnam and Ethiopia: a study protocol for a multi-country cluster randomised controlled trial," Trials. 19(1): 420. doi: 10.1186/s13063-018-2815-0

27. de Molina-Férnandez, M. I. et al. 2019. "The effectiveness of a digital shared decision-making tool in hormonal contraception during clinical assessment: study protocol of a randomized controlled trial in Spain," BMC Public Health. 19(1): 1224. doi: 10.1186/s12889019-7572-9

28. Leon, F. R. et al. 2005. "Providers' compliance with the Balanced Counseling Strategy in Guatemala," Stud Fam Plann. 36(2): 117-26. doi: 10.1111/j.1728-4465.2005.00049.x

29. Liambila, W. et al. 2008. "Feasibility, acceptability, effect, and cost of integrating counseling and testing for HIV within family planning services in Kenya," FRONTIERS Final Report [Internet]. Washington, DC: Population Council. Available from: https://knowledgecommons.popcouncil.org/departments_sbsr-rh/433. doi: 10.31899/rh4.1180

30. Festin, M. P. R. 2012. "Simplified WHO Decision Making Tool and counseling guide on family planning for community health workers and their clients," Int J Gynecol Obstet. 119(S3): S349-S349. doi: 10.1016/S0020-7292(12)60682-1

31. Munro, S. et al. 2019. "Investigation of factors influencing the implementation of two shared decision-making interventions in contraceptive care: a qualitative interview study among clinical and administrative staff," Implement Sci. 14(1): 95. doi: 10.1186/s13012019-0941-z

32. Madrigal, J. M. 2019. "The family planning quotient and reproductive life index (FPQ/RepLI) tool: a solution for family planning, reproductive life planning and contraception counseling," Reprod Health. 16(1): 125. doi: 10.1186/s12978-019-0787-5

33. Ahmad, J. et al. 2014. "Evaluation of the feasibility, utility, and effects of the use of family planning tools at the community level in India." New York: Population Council.

34. Nawar, L. et al. 2004. "Impact of improved client-provider interaction on women's achievement of fertility goals in Egypt [Internet]," FRONTIERS Final Report. Washington, DC: Population Council. Available from:

https://knowledgecommons.popcouncil.org/departments_sbsr-rh/387 doi: 10.31899/rh4.1134

35. Leon, F. et al. 2004. "Effects of IGSS' job aids-assisted Balanced Counseling Algorithms on quality of care and client outcomes [Internet]," FRONTIERS Final Report. Washington, DC: Population Council. Available from: https://knowledgecommons.popcouncil.org/departments_sbsr-rh/404 doi: 10.31899/rh4.1151

36. Leon, F. et al. 2003. "One-year client impacts of quality of care improvements achieved in Peru [Internet]," FRONTIERS Final Report. Washington, DC: Population Council. Available from: https://knowledgecommons.popcouncil.org/departments_sbsr-rh/449 doi: $10.31899 / \mathrm{rh} 4.1196$

37. Leon, F. "Peru: Providers' compliance with quality of care norms [Internet]," FRONTIERS Final Report. Washington, DC: Population Council. 1999 Jan. Available from: https://knowledgecommons.popcouncil.org/departments_sbsr-rh/451 doi: 10.31899/rh4.1198

38. León, F. et al. 2003. "Enhancing quality for clients: the Balanced Counseling Strategy [Internet]," FRONTIERS Program Brief No. 3. Washington, DC: Population Council. Available from: / paper/Enhancing-quality-for-clients\%3A-the-balanced-FrR\%C3\%ADos/c7996cfb839b17665e2c7820b5c4493efe9fb304

39. Liambila, W. et al. 2009. "Feasibility and effectiveness of integrating provider-initiated testing and counselling within family planning services in Kenya," AIDS 23(Suppl 1): S115-121. doi: 10.1097/01.aids.0000363784.96321.43 
40. Kim, Y. M. et al. 2005. "Promoting informed choice: evaluating a decision-making tool for family planning clients and providers in Mexico," Int Fam Plan Perspect. 31(4): 162-71. doi: 10.1363/3116205

41. Kim, Y. M. et al. 2007. "Evaluation of the World Health Organization's family planning decision-making tool: Improving health communication in Nicaragua," Patient Educ Couns. 66(2): 235-42. doi: 10.1016/j.pec.2006.12.007

42. Johnson, S. L., Y. M. Kim, and K. Church. 2010. "Towards client-centered counseling: Development and testing of the WHO DecisionMaking Tool," Patient Educ Couns. 81(3): 355-61. doi: 10.1016/j.pec.2010.10.011

43. Langston, A. M., L. Rosario, and C. L. Westhoff. 2010. "Structured contraceptive counseling-a randomized controlled trial," Patient Educ Couns. 81(3): 362-7. doi: 10.1016/j.pec.2010.08.006

44. Garbers, S. et al. 2012. "Tailored health messaging improves contraceptive continuation and adherence: results from a randomized controlled trial," Contraception. 86(5): 536-42. doi: 10.1016/j.contraception.2012.02.005

45. Garbers, S. et al. 2012. "Randomized controlled trial of a computer-based module to improve contraceptive method choice," Contraception. 86(4): 383-90. doi: 10.1016/j.contraception.2012.01.013

46. Gilliam, M. L. et al. 2014. "Development and testing of an iOS waiting room "app" for contraceptive counseling in a Title X family planning clinic," Am J Obstet Gynecol. 211(5): 481.e1-481.e8. doi: 10.1016/j.ajog.2014.05.034

47. Sridhar, A. and A. Y. Chen. 2014. "Mobile health application for long-acting reversible contraceptive information: a secondary analysis," Obstet Gynecol. 123(Supplement 1): 111S. doi: 10.1097/01.AOG.0000447055.56470.d6

48. Sridhar, A. 2015. "Mobile application for information on reversible contraception: a randomized controlled trial," Am J Obstet Gynecol. 212(6): 774.e1-774.e7. doi: 10.1016/j.ajog.2015.01.011

49. Gressel, G. M. et al. 2014. "Patient and provider perspectives on Bedsider.org, an online contraceptive information tool, in a low income, racially diverse clinic population," Contraception. 90(6): 588-93. doi: 10.1016/j.contraception.2014.07.010

50. Antonishak, J., K. Kaye, and L. Swiader. 2015. "Impact of an online birth control support network on unintended pregnancy," Soc Mark Q. 21(1): 23-36. doi: 10.1177/1524500414566698

51. Tancredi, D. J. et al. 2015. "Cluster randomized controlled trial protocol: addressing reproductive coercion in health settings (ARCHES). BMC Womens Health. 15(1): 57. doi: 10.1186/s12905-015-0216-z

52. Miller, E. et al. 2016. "A family planning clinic-based intervention to address reproductive coercion: a cluster randomized controlled trial," Contraception. 94(1): 58-67. doi: 10.1016/j.contraception.2016.02.009

53. Miller, E. et al. 2011. "A family planning clinic partner violence intervention to reduce risk associated with reproductive coercion," Contraception. 83(3): 274-80. doi: 10.1016/j.contraception.2010.07.013

54. Uysal, J. et al. 2020. "Protocol for a matched-pair cluster control trial of ARCHES (Addressing Reproductive Coercion in Health Settings) among women and girls seeking contraceptive services from community-based clinics in Nairobi, Kenya," Reprod Health. 17(1): 77. doi: 10.1186/s12978-020-00916-9

55. Chuang, C. H. et al. 2015. "Reducing unintended pregnancies through web-based reproductive life planning and contraceptive action planning among privately insured women: study protocol for the MyNewOptions randomized, controlled trial," Womens Health Issues. 25(6): 641-8. doi: 10.1016/j.whi.2015.06.010

56. Chuang, C. et al. 2017. "Does reproductive life planning work? Results from the MyNewOptions study," Contraception. 96(4): 282. doi: 10.1016/j.contraception.2017.07.078

57. Jamin, C. G. et al. 2017. "Development and conceptual validation of a questionnaire to help contraceptive choice: CHLOE (Contraception: HeLping for wOmen's choicE)," Eur J Contracept Reprod Health Care. 22(4): 286-90. doi: 10.1080/13625187.2017.1364719

58. Marshall C. et al. 2017. "Patient perceptions of a decision support tool to assist with young women's contraceptive choice," Patient Educ Couns. 100(2): 343-8. doi: 10.1016/j.pec.2016.08.022

59. Johns Hopkins Center for Communication Programs. 2021. "Digital counseling app helps women make better family planning choices [Internet]," 8 March [cited 2021 May 23]. Available from: https://ccp.jhu.edu/2021/03/08/digital-counseling-app-family-planningchoices/ 
60. Population Council. 2015. The Balanced Counseling Strategy Plus: A Toolkit for Family Planning Service Providers Working in High HIV/STI Prevalence Settings (Third Edition) [Internet]. [cited 2021 Jun 6]. Available from: https://www.popcouncil.org/research/the-balancedcounseling-strategy-plus-a-toolkit-for-family-planning-service doi: 10.31899/rh9.1095

61. Thompson, R. et al. 2017. "Right For Me: protocol for a cluster randomised trial of two interventions for facilitating shared decision-making about contraceptive methods," BMJ Open. 7(10): e017830. doi: 10.1136/bmjopen-2017-017830

62. Dev, R. et al. 2019. "Acceptability, feasibility and utility of a mobile health family planning decision aid for postpartum women in Kenya," Reprod Health. 16(1): 97. doi: 10.1186/s12978-019-0767-9

63. Balkus, J. E. et al. 2016. "An empiric HIV risk scoring tool to predict HIV-1 acquisition in African women," JAIDS J Acquir Immune Defic Syndr. 72(3): 333-43. doi: 10.1097/QAI.0000000000000974

64. Kahle, E. M. et al. 2013. "An empiric risk scoring tool for identifying high-risk heterosexual HIV-1-serodiscordant couples for targeted HIV1 prevention," JAIDS J Acquir Immune Defic Syndr. 62(3): 339-47. doi: 10.1097/QAl.0b013e31827e622d

65. Scott, H. et al. 2020. "Development and validation of the personalized sexual health promotion (SexPro) HIV risk prediction model for men who have sex with men in the United States," AIDS Behav. 24(1): 274-83. doi: 10.1007/s10461-019-02616-3

66. Ayton, S. G. et al. 2020. "Development of a prognostic tool exploring female adolescent risk for HIV prevention and PrEP in rural South Africa, a generalised epidemic setting," Sex Transm Infect. 96(1): 47-54. doi: 10.1136/sextrans-2019-054067

67. Luo, Q. et al. 2019. "External validation of a prediction tool to estimate the risk of human immunodeficiency virus infection amongst men who have sex with men," Medicine (Baltimore) 98(29): e16375. doi: 10.1097/MD.0000000000016375

68. Mugwanya, K. K. et al. 2019. "Integrating preexposure prophylaxis delivery in routine family planning clinics: A feasibility programmatic evaluation in Kenya," PLOS Med. 16(9): e1002885. doi: 10.1371/journal.pmed.1002885

69. International Planned Parenthood Federation. 2002. "Learning from the field experiences in HIV prevention from family planning associations worldwide." London: International Planned Parenthood Federation.

70. Pintye, J. et al. 2016. "A risk assessment tool for identifying pregnant and postpartum women who may benefit from pre-exposure prophylaxis (PrEP)," Clin Infect Dis. 64(6):751-758. doi: 10.1093/cid/ciw850.

71. Dehlendorf, C., C. Krajewski, and S. Borrero. 2014. "Contraceptive counseling: best practices to ensure quality communication and enable effective contraceptive use," Clin Obstet Gynecol. 57(4): 659-73. doi: 10.1097/GRF.0000000000000059 
4301 Connecticut Avenue NW, Suite 280 Washington, DC 20008

popcouncil.org 